\title{
Competitividade e mudança institucional na cadeia produtiva de plantas medicinais no Brasil*
}

\author{
Institutional change and competitiveness in the productive chain of medicinal \\ plants in Brazil
}
Compétitivité et des changements institutionnels dans la chaîne de production de plantes médicinales au Brésil

\author{
Competitividad y cambio institucional en la cadena de producción de las plantas \\ medicinales en Brasil
}

\author{
Waldecy Rodrigues** \\ (waldecy@terra.com.br)
}

Recebido em 07/07/15; revisado e aprovado em 10/09/15; aceito em 09/10/15

DOI: http://dx.doi.org/10.20435/1984042X2016210

\begin{abstract}
Resumo: O Brasil possui uma das maiores reservas de biodiversidade do planeta, continua apresentando um baixo nível de competitividade revelada na cadeia produtiva de plantas medicinais e um dos motivos são os entraves burocráticos e institucionais do país. Com a aprovação da Política Nacional de Práticas Integrativas e Complementares (PNPIC) no SUS, a Política Nacional de Plantas Medicinais e Fitoterápicos (PNPMF) e a criação da categoria de "Produtos Tradicionais Fitoterápicos" (RDC 26/2014 - ANVISA), espera-se a melhoria das condições de competitividade sistêmica no setor.

Palavras-chave: Plantas medicinais; medicamentos fitoterápicos; cadeias produtivas da biodiversidade.

Abstract: The Brazil has one of the largest reservoirs of biodiversity of the planet, continues showing a low level of competition revealed in the production chain of medicinal plants and one of the reasons are the bureaucratic and institutional in the country. With the approval of the National Policy of Integrative and Complementary Practices (PNPIC) in the SUS National Policy of Medicinal Plants and Herbal Remedies (PNPMF) and the creation of the category of "Traditional Herbal Products" (DRC 26/2014-ANVISA), it is expected to improve the conditions of systemic competitiveness in the sector.
\end{abstract}

Key words: Medicinal plants; medicinal phytotherapy; production chains of biodiversity.

Résumé: Le Brésil possède l'un des plus grands réservoirs de biodiversité de la planète, continue présentant un faible niveau de la concurrence a révélé dans la chaîne de production de plantes médicinales et l'une des raisons sont la bureaucratiques et institutionnelles du pays. Avec l'approbation de la Politique Nationale d'Intégrative et Pratiques Complémentaires (PNPIC) dans le National SUS Politique des Plantes Médicinales et Plantes Médicinales (PNPMF) et la création de la catégorie des "Produits à bAse de Plantes Traditionnelles" (RDC 26/2014-ANVISA), devrait améliorer les conditions de compétitivité systémique dans le secteur. Mots-clés: plantes médicinales; remèdes naturels; la biodiversité chaînes productives.

Resumen: Brasil tiene una de las mayores reservas de biodiversidad del planeta continúa mostrando un bajo nivel de competitividad revelada en la cadena productiva de plantas medicinales, una de las razones es barreras burocráticas e institucionales del país. Se espera - Con la aprobación de la Política Nacional de Prácticas Integrativas y Complementarias (PNPIC) en el SUS, la Política Nacional de Plantas Medicinales y Medicamentos Herbarios (PNPMF) y la creación de la categoría de "Traditional Herbal Products" (ANVISA RDC 26/2014) mejorar las condiciones de competitividad sistémica en el sector.

Palabras clave: plantas medicinales; hierbas medicinales; las cadenas de producción de la biodiversidad.

\section{INTRODUÇÃO}

O Brasil é considerado como um dos países com maiores perspectivas para a exploração econômica da biodiversidade do planeta. É o país com maior número de espécies animais e vegetais do mundo, contando com um número estimado entre $15 \%$ a $20 \%$ do total. A maioria das plantas existentes é encontrada nos países tropicais, e estima-se que aproximadamente $25 \%$ das espécies ocorram originalmente no Brasil. Como estamos utilizando economicamente nossa biodiversidade? Somos competitivos na fabricação de produtos derivados da biodiversidade, em especial na cadeia produtiva de plantas medicinais? Como vem evoluindo o recente marco regulatório e como isto vem

\footnotetext{
* Pesquisa financiada com recursos do Conselho Nacional de Desenvolvimento Científico e Tecnológico (CNPq).

** Universidade Federal do Tocantins, Palmas, Tocantins, Brasil.
} 
repercutindo sobre os indicadores da competitividade da cadeia produtiva de plantas medicinais no país?

Rodrigues e Nogueira (2008) concluem, em seu trabalho, que o Brasil é um grande importador líquido em todos os segmentos da cadeia produtiva de plantas medicinais, com déficits comerciais crescentes na medida em que os produtos têm maiores valores adicionados. Apontam para a necessidade de se ter um marco regulatório mais flexível, que estimule o investimento e a produção de medicamentos fitoterápicos no Brasil. Este artigo retoma essa análise, avaliando a competitividade dessa cadeia produtiva, a partir de indicadores advindos do comércio exterior entre os anos de 2000 a 2011.

Aproximadamente 25 mil espécies de plantas são usadas em todo o mundo para a produção de medicamentos, incluindo não somente aqueles obtidos por síntese a partir de produtos naturais, mas também os medicamentos comercializados como produtos fitoterápicos. Das espécies nativas brasileiras não mais que $1 \%$ foi objeto de pesquisas quanto ao seu potencial uso bioeconômico (BRAGA, 2002).

Carvalho et al. (2008a) estimam que haja 512 medicamentos fitoterápicos registrados na ANVISA derivados de aproximadamente 162 extratos de plantas medicinais e outros derivados. Apesar de o país possuir um grande número de espécies do planeta e ter uma longa aceitação de uso de plantas medicinais entre a população (RODRIGUES; NOGUEIRA, 2008), apenas $25 \%$ dos medicamentos fitoterápicos registrados no Brasil vêm de espécies medicinais existentes na América do Sul (CARVALHO et al., 2008b).

Os medicamentos fitoterápicos representam uma porção significativa do mercado mundial de medicamentos, com crescimento nas vendas de $15 \%$ ao ano contra $4 \%$ do setor de fármacos sintéticos. No Brasil, eles geram uma receita de aproximadamente US\$ 160 milhões anuais, constituindo um mercado promissor e em franca expansão. Observa-se que grande parte dos fitoterápicos apresenta rentabilidade elevada, desmistificando a justificativa das empresas se manterem ilegais devido a pouca significância econômica desse mercado (CARVALHO et al., 2011c). Esses dados apontam para uma grande janela de oportunidades para atendimento do mercado interno, e, dada a riqueza de nossa biodiversidade, um enorme potencial para o desenvolvimento de novos produtos para a exportação. Então, se as condições são aparentemente favoráveis, então por que não somos internacionalmente competitivos em um setor em que apresentamos vantagens comparativas aparentes?

\section{MATERIAIS E MÉTODOS}

Como a competitividade de uma cadeia produtiva pode ser medida? Existem diferenças entre padrões e indicadores de competitividade entre cadeias produtivas de baixo e alto conteúdo tecnológico? Em regra, nas tradições clássicas e neoclássicas da ciência econômica, a competitividade é vista como o fruto de um uso mais eficiente e intensivo dos fatores de produção, sendo os indicadores mais significativos para sua medição: os custos de produção e a produtividade dos insumos utilizados. Em termos de comércio exterior, essas abordagens são representadas pelas clássicas teorias do comércio internacional de Smith e Ricardo, passando pelo tradicional modelo neoclássico Heckscher-Ohlin-Samuelson, onde se considera que se pode medir a eficiência na alocação de fatores a partir do conhecimento de quais produtos os países se especializam no comércio internacional.

Várias críticas significativas foram realizadas à visão clássica e neoclássica sobre competitividade dentro e fora do mainstream ${ }^{1}$. Dentre elas, é de interesse desta análise a crítica da nova economia institucional e a crítica do evolucionismo schumpteriano. Sem entrar exaustivamente nas discussões de natureza mais teórica, a principal contribuição da Nova Economia Institucional (NEI) foi despertar para a relevância que o ambiente institucional tem sobre a competitividade das cadeias produtivas, principalmente pela existência dos custos de transação. Já a crítica evolucionista destaca que tão ou mais significativo que perceber a competitividade revelada, é

\footnotetext{
1 Adjetivo dado às análises econômicas ligadas ao livre mercado e livre cambismo, fundamentalmente ligado à tradição neoclássica de Walras, Jevons e Marshall (dentre outros).
} 
entender como se dá o processo dinâmico de inovação em direção a esses parâmetros de competitividade.

Assim, GADELHA (2006) considera que, especialmente para as atividades ligadas ao setor de saúde, e nós expandimos para aos demais setores biotecnológicos, convém considerar os argumentos evolucionistas para perceber a competitividade sistêmica, principalmente em cadeias produtivas em que a evolução tecnológica tem uma condição significativa. Nesse contexto, os aspectos relacionados à inovação e à política industrial são essenciais para compreender as potencialidades ou gargalos sistêmicos em situações competitivas, principalmente aquelas em que a inovação tecnológica é uma variável fundamental.

Existe uma grande carência na disponibilidade e nos recortes de dados nas cadeias produtivas biotecnológicas brasileiras, particularmente, na de plantas medicinais. Não existe ainda dados sistematizados do IBGE (Instituto Brasileiro de Geografia e Estatística) para o setor, o que impossibilita o acompanhamento da evolução de indicadores sobre a sua competitividade, tais como a evolução da produção, emprego, massa salarial, dentre outros. Uma das proxies encontradas e já tradicionalmente utilizadas em pesquisas do Complexo Industrial da Saúde é a utilização de dados de comércio exterior, conforme outras pesquisas realizadas por Ferreira (1998) e Gadelha (2003; 2006).

Metodologicamente nesta pesquisa, em primeiro lugar é realizada a análise da cadeia produtiva de plantas medicinais. A perspectiva metodológica da análise de cadeia produtiva aqui adotada segue a perspectiva de Lazzarini et al. (2001) e Rodrigues e Nogueira (2008) que privilegiam a visão das transações em redes e de sua integração ao mercado internacional, mais adequada às cadeias produtivas de maior valor agregado.

Em segundo lugar, foi realizada a sistematização das categorias da Nomenclatura Comum de Mercadorias (NCM) no recorte da Cadeia Produtiva de Plantas Medicinais. A partir do trabalho desenvolvido por Ferreira (1998), os produtos foram reclassificados da antiga Nomenclatura Brasileira de Mercadorias (NBM) para a Nomenclatura Comum de Mercadorias (NCM). Notou-se que realmente existe uma grande dificuldade para a dimensão da evolução particular de alguns produtos da cadeia produtiva, tais como planta medicinal in natura, sucos e extratos, princípios ativos e medicamentos advindos de plantas medicinais, devido à existência de categorias bastante genéricas na antiga NBM e, principalmente, na atual NCM. Após, as classificações e a verificação dos valores de importação e exportação dos produtos no Sistema Aliceweb ${ }^{2}$, estes foram agrupados por segmentos pré-estabelecidos da cadeia produtiva de plantas medicinais: plantas medicinais e suas partes, sucos e extratos a partir de plantas medicinais, princípios ativos a partir das plantas medicinais e medicamentos e fármacos a partir de plantas medicinais. Logo após, foram calculados o saldo comercial geral e das categorias e o preço médio das importações e exportações.

\section{EVOLUÇÃO DO MARCO REGULATÓRIO NA CADEIA PRODUTIVA DE PLANTAS MEDICINAIS NO BRASIL}

Rodrigues e Nogueira (2008) destacam que, no Brasil, existe uma fraca relação do ponto de vista da inovação na cadeia produtiva de plantas medicinais. Isso é representado pela pequena quantidade de plantas medicinais brasileiras que tiveram a requisição de registro para produção de medicamentos junto à Agência Nacional de Vigilância Sanitária (ANVISA). Isso demonstra que o potencial brasileiro na exploração econômica da biodiversidade é muito pouco aproveitado. Por que isto ocorre? Algumas hipóteses podem ser levantadas: 1) a grande oligopolização do setor de medicamentos e fármacos no plano nacional e internacional inibe investimentos de pequenos e médios laboratórios brasileiros que concorrem no setor; 2) o alto custo dos procedimentos de pesquisa exigidos pela atual legislação, levando a grande incerteza no retorno dos investimentos realizados; 3 ) ausência de uma política industrial e tecnológica mais efetiva para o estímulo de pesquisas e exploração econômica das plantas

\footnotetext{
2 Sistema de informação pertencente ao Ministério de Desenvolvimento, Indústria e Comércio. Maiores detalhes ver em: <www.desenvolvimento.gov.br>.
} 
medicinais; 4) falta de uma legislação mais moderna, relacionada à definição de direitos de propriedade, que permita aos laboratórios brasileiros investirem na produção de medicamentos a partir de plantas medicinais.

Por esse conjunto de razões elencadas, as grandes fontes de biodiversidade são as florestas tropicais, localizadas em países em desenvolvimento como o Brasil, detendo aproximadamente um terço da flora mundial. Porém os países desenvolvidos, como EUA, Japão e os europeus, são os que mais manufaturam e comercializam produtos naturais. No desenvolvimento e produção de um medicamento fitoterápico, os custos são elevados, como em qualquer medicamento alopático, e esses países investem montantes superiores aos países em desenvolvimento como o Brasil.

Nesse processo de pesquisa e desenvolvimento (P\&D), pode-se afirmar que, nos primeiros dez anos, os custos estão todos vinculados à pesquisa e desenvolvimento, $\mathrm{e}$ não ao retorno dos investimentos. Essa situação só começa a mudar a partir do $11^{\circ}$ ano, quando os custos com pesquisa e desenvolvimento caem e são desviados para custos de produção e vendas, chegando a ser zero após 19 e 20 anos, quando começam a surgir os lucros. Nesse contexto, espera-se que novos produtos possam ser desenvolvidos a partir de espécies nativas, por meio de compromissos institucionais (universidade e empresa), com a aplicação de recursos que garantam a atuação de especialistas das áreas da Botânica, Biologia, Agronomia, Farmácia, Química e Medicina (YUNES et al., 2001).

No Brasil, o mercado de fitoterápicos é formado hoje por cerca de duzentos laboratórios fabricantes no país, movimenta em torno de US\$ 400 milhões (quatrocentos milhões de dólares) e representa apenas 6,7\% das vendas de medicamentos no país, sendo um mercado promissor e em franca expansão. Por exemplo, o líder de mercado do seguimento, o Vick Vaporub®, desenvolvido por uma empresa multinacional, fatura em média US\$ 20 milhões (vinte milhões de dólares) por ano. Outros produtos como o Tebonim $\AA^{\circledR}$ Transpulmin $₫$, Eparema ${ }^{\circledR}$, Atroveran $\AA$, Reparil ${ }^{\circledR}$, Valmane ${ }^{\circledR}$ e o Chophytol ${ }^{\circledR}$ apresentam rentabilidades bastante elevadas, desmistificando de forma definitiva a ilegalidade desse mercado ou sua pouca significância financeira (ALVES et al., 2008).
O Brasil tem conhecimento científico sobre um percentual, ainda que baixo, das plantas destinadas ao uso medicinal, e as empresas brasileiras têm capacitação necessária para gerar processos tecnológicos, no entanto não possuem um corpo de $\mathrm{P} \& \mathrm{D}$ capaz de gerar inovações na área de medicamentos fitoterápicos e produtos naturais de forma contínua. Com o uso sustentável da biodiversidade nacional e desenvolvimento de parcerias da Universidade com as empresas, alguns desafios poderão ser suplantados para gerar novas possibilidades nesse campo (CARVALHO et al., 2011c).

As barreiras mais fortes para o uso das plantas medicinais na indústria nacional são, por um lado, os elevados custos com pesquisa, o que vai da prospecção da planta medicinal até a fase dos testes pré-clínicos e clínicos. Para o enfrentamento dessa questão, necessita-se de uma revisão da política industrial e tecnológica brasileira para o setor, onde instrumentos de crédito e de promoção comercial precisam ser reforçados, bem como os mecanismos de normatização da produção dos medicamentos fitoterápicos precisam ser revistos (RODRIGUES; NOGUEIRA, 2008).

Para as lideranças empresariais do setor, particularmente, a indústria fitoterápica nacional está vivenciando uma situação de crise permanente, principalmente, a partir do ano 2000, quando foi publicada a $\mathrm{RDC}^{3}$ 17/2000 - ANVISA, que trouxe novos critérios para o registro dos medicamentos fitoterápicos. Esses critérios impediram ou dificultaram o registro de plantas medicinais nacionais em benefício das plantas estrangeiras. Dessa forma, as empresas brasileiras foram obrigadas a ampliar sua importação de matérias-primas com o consequente aumento em seus custos de fabricação (ABIFISA, 2007).

No ano 2002, foi encaminhada à Câmara Federal uma proposta para a modernização da legislação brasileira para obtenção de registro para medicamentos fitoterápicos. Essa proposta, inspirada na legislação canadense que regulamenta os Natural Health Products (produtos de origem natural para a saúde), cria uma nova categoria denominada Produtos para Promoção da Saúde (PPS) em que se inclui a maior parte dos medicamentos

\footnotetext{
Resolução da Diretoria Colegiada.
} 
fitoterápicos brasileiros. A legislação proposta retira a necessidade da realização de testes clínicos desses produtos, que devem ter a qualidade e segurança comprovada, porém a eficácia deve ser respaldada na evidência científica ou em literatura que comprove seu uso etnocultural. Entre as lideranças empresariais do setor, há uma expectativa de que essa mudança possa impulsionar toda a cadeia produtiva, estimulando desde a exploração ordenada das plantas medicinais até a produção de medicamentos fitoterápicos (RODRIGUES; NOGUEIRA, 2008).

A partir do ano de 2006, começaram a ocorrer grandes mudanças no marco regulatório relacionado ao de plantas medicinais e a fabricação de produtos nacionais e medicamentos fitoterápicos. Nesse ano, o governo brasileiro aprovou a Política Nacional de Práticas Integrativas e Complementares (PNPIC) no Sistema Único de Saúde (SUS) e a Política Nacional de Plantas Medicinais e Fitoterápicos (PNPMF), as quais fomentam pesquisas sobre plantas medicinais e desenvolvimento de fitoterápicos de qualidade, priorizando a proteção da biodiversidade (CARVALHO et al., 2011).

Em 2013, a ANVISA publicou dispositivo específico (RDC 13/2013) sobre boas práticas de fabricação para Produtos Tradicionais Fitoterápicos. Com a RDC 26/2014 foram criadas duas modalidades de produtos, os "medicamentos fitoterápicos", que continuam tendo a necessidade de passar por testes clínicos padronizados para avaliação de segurança e eficácia; e os "produtos tradicionais fitoterápicos", que serão autorizados por meio da demonstração do uso seguro no ser humano por um período longo, determinado pela Agência como de 30 anos, mediante a literatura científica referenciada.

A ANVISA publicará ainda as listas de registro simplificado, conhecida por "Lista de medicamentos fitoterápicos de registro simplificado" e a "Lista de produtos tradicionais fitoterápicos de registro simplificado", englobando 43 plantas para quais a Agência reconhecerá a segurança, eficácia e efetividade, devido a uma grande quantidade de dados já existentes publicados sobre as espécies.

Com isto ficará muito mais simples e bem menos onerosa a obtenção de registros para a fabricação de produtos tradicionais fitoterápicos, o que possibilitará um ambiente para o surgimento de novas oportunidades para as empresas. Antes da RDC 26/2014, somente era possível entrar de forma legal no setor, com um investimento mínimo aproximado de R $\$ 7$ milhões, agora será possível fabricar produtos tradicionais fitoterápicos, com investimentos abaixo de $\mathrm{R} \$ 1$ milhão de reais ${ }^{4}$, isto obviamente dependendo da dimensão da planta produtiva, sem contar, as possibilidades que surgirão para a formação de cooperativas de produção nas comunidades tradicionais que detêm o saber popular das plantas medicinais.

Assim, espera-se um grande estímulo ao setor com a criação dos produtos tradicionais fitoterápicos. Porém os desafios mais complexos no isolamento de princípios ativos para o fortalecimento da indústria nacional de medicamentos fitoterápicos ainda permanecerão, pois estes prescindirão dos testes de validação laboratorial. Todavia, com essa janela de oportunidade, o Brasil poderá avançar, e muito, no uso de sua biodiversidade com a geração de produtos de alto valor agregado. Sem dúvida, um grande avanço para nossa economia da biodiversidade, que, para ser mais bem aproveitada, dependerá do conjunto de outras políticas e estratégicas, mas, grandes passos já foram dados com as mudanças institucionais empreendidas.

\section{EVOLUÇÃO DO COMÉRCIO EXTERIOR DA CADEIA PRODUTIVA DE PLANTAS MEDICINAIS NO BRASIL}

Como anda a competividade internacional da cadeia produtiva de plantas medicinais no país? O Brasil ainda não conseguiu desenvolver uma indústria fitoterápica própria, mesmo possuindo grande biodiversidade e publicando vários estudos sobre o assunto. $\mathrm{O}$ país importa produtos fitoterápicos da China e Índia, enquanto laboratórios estrangeiros patenteiam complexos fitoterápicos à base de plantas brasileiras. O país tem potencial para ser um grande polo de plantas medicinais no mundo, colocando no mercado farmacêutico substâncias processadas e com valor tecnológico agregado, e não servindo como mero

\footnotetext{
${ }^{4}$ Dados colhidos em entrevistas com empresários do setor.
} 
fornecedor de matéria-prima. Para se inserir no mercado internacional, é indispensável o desenvolvimento do setor de regulação, aliado à adequação das empresas à legislação vigente (ALVES et al., 2008).

A tabela 1 demonstra, a partir dos dados do comércio exterior, indicadores de competitividade revelada da cadeia produtiva de plantas medicinais no Brasil. Em regra, o Brasil continua ser um importador líquido em todos os segmentos da cadeia produtiva. No ano de 2011, as importações foram proporcionalmente maiores no segmento de medicamentos a partir de plantas medicinais $(91,3 \%)$, seguidos por princípios ativos a partir de plantas medicinais $(6,8 \%)$, sucos e extratos a partir de plantas medicinais $(1,0 \%)$ e plantas medicinais e suas partes $(0,8 \%)$.

No período entre 2000 /2011, o déficit comercial de toda a cadeia produtiva ampliou $136,7 \%$. Esse indicador saiu de U\$778 mil em 2000 para U\$1.842 milhões em 2011. No período em análise, as importações aumentaram 156,2\% chegando em 2011 a U\$ 2.4 bilhões. Já as exportações cresceram 250,9\% chegando em 2011 a U\$ 561 milhões. Apesar do bom crescimento relativo das exportações no período, isto não retira o forte caráter de importador líquido que o Brasil assume na cadeia produtiva de plantas medicinais. 


\begin{tabular}{|c|c|c|c|c|c|c|c|c|c|c|c|c|c|c|c|c|}
\hline तี & $\begin{array}{l}\text { 오․ } \\
\vec{F}\end{array}$ & 艼 & 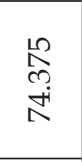 & \begin{tabular}{l}
$\sqrt{5}$ \\
$\infty$ \\
$\ddot{P}$ \\
\multirow{4}{*}{}
\end{tabular} & 令 & $\begin{array}{l}\hat{N} \\
\text { m. } \\
\text { तิ }\end{array}$ & 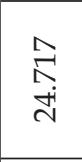 & 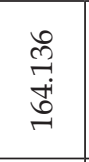 & $\begin{array}{l}\infty \\
\hat{\omega} \\
\infty \\
\sigma \\
\sigma \\
\vec{\lambda}\end{array}$ & 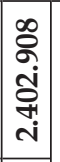 & & $\begin{array}{l}\hat{R} \\
\text { o. } \\
\text { o. }\end{array}$ & $\begin{array}{l}\widehat{N} \\
\text { à } \\
\text { త్ర }\end{array}$ & 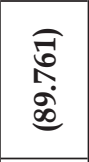 & 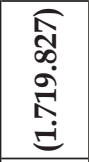 & 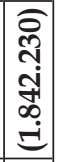 \\
\hline 옳 & $\begin{array}{l}\hat{n} \\
\hat{n} \\
\sigma\end{array}$ & $\underset{\infty}{\overrightarrow{0}}$ & $\begin{array}{l}\text { 号 } \\
\text { †े } \\
\infty\end{array}$ & 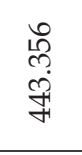 & 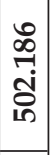 & $\begin{array}{l}\infty \\
0 \\
0 \\
0\end{array}$ & 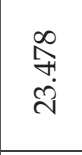 & $\begin{array}{l}\infty \\
\infty \\
\stackrel{0}{0} \\
\stackrel{N}{-1}\end{array}$ & $\begin{array}{l}\text { ô } \\
\text { N̦ } \\
\stackrel{8}{8} \\
\stackrel{i}{i}\end{array}$ & 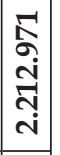 & & $\begin{array}{l}\overline{8} \\
\stackrel{\Xi}{\oplus}\end{array}$ & 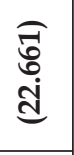 & 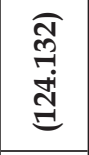 & 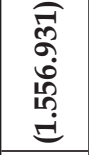 & 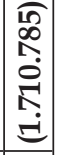 \\
\hline ठ্ণે & $\begin{array}{l}\text { 坚 } \\
\stackrel{2}{2}\end{array}$ & $\begin{array}{l}\infty \\
\infty \\
\infty\end{array}$ & $\begin{array}{l}\text { ते } \\
\text { ڤ్ } \\
\vec{\forall}\end{array}$ & $\begin{array}{l}\text { के } \\
\text { तें } \\
\text { yे }\end{array}$ & 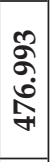 & $\begin{array}{l}\circ \\
\vdots \\
\dot{J}\end{array}$ & $\begin{array}{l}\stackrel{M}{ت} \\
\vec{J}\end{array}$ & 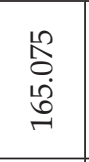 & 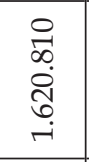 & 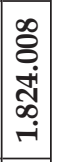 & & $\begin{array}{l}\sqrt{n} \\
0 \\
0 \\
0 \\
0\end{array}$ & 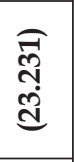 & 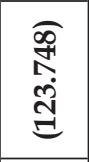 & 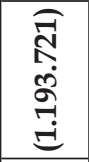 & 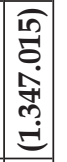 \\
\hline 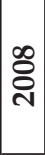 & 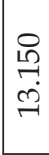 & $\stackrel{ }{ }$ & $\begin{array}{l}\hat{10} \\
\infty \\
0 \\
\stackrel{-}{7}\end{array}$ & 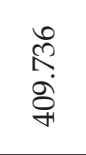 & 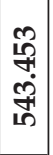 & 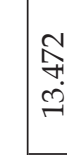 & $\begin{array}{l}\text { ڤ̊ } \\
\text { तે }\end{array}$ & 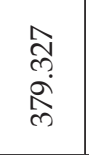 & 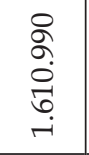 & 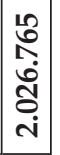 & & 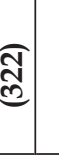 & 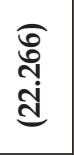 & 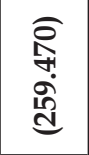 & 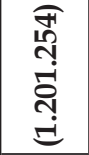 & 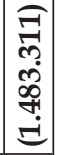 \\
\hline ڤ્ণે & $\begin{array}{l}\text { त̃ } \\
\text { } \\
\sigma\end{array}$ & $\begin{array}{l}\stackrel{2}{\alpha} \\
\text { ळे }\end{array}$ & $\begin{array}{l}\infty \\
\infty \\
\infty \\
10 \\
\infty \\
\infty\end{array}$ & $\begin{array}{l}\text { o } \\
\text { तె } \\
\text { ల్ల }\end{array}$ & \begin{tabular}{l}
2 \\
$\infty$ \\
0 \\
0 \\
\hdashline \\
$\forall$
\end{tabular} & $\begin{array}{l}\stackrel{8}{8} \\
\stackrel{8}{0}\end{array}$ & $\begin{array}{l}8 \\
\stackrel{1}{0} \\
\text { ¿े. }\end{array}$ & 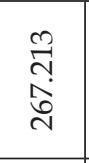 & 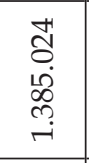 & 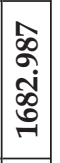 & & $\stackrel{\mathbb{S}}{\mathrm{S}}$ & $\begin{array}{l}\hat{0} \\
\stackrel{8}{8} \\
\stackrel{0}{0}\end{array}$ & 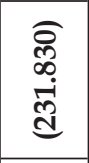 & 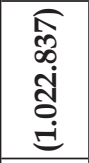 & 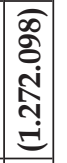 \\
\hline & 营 & 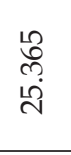 & 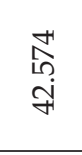 & 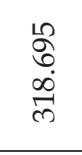 & 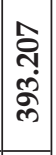 & 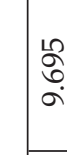 & 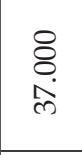 & 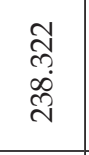 & $\begin{array}{l}10 \\
\infty \\
10 \\
\sim \\
\infty \\
0 \\
- \\
\end{array}$ & 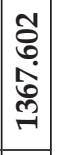 & & $\begin{array}{c}\widehat{\vec{c}} \\
\stackrel{0}{0}\end{array}$ & 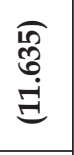 & 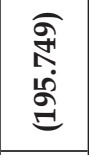 & 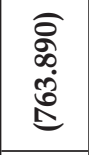 & 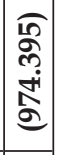 \\
\hline 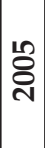 & 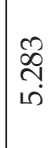 & 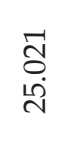 & $\begin{array}{l}\vec{\infty} \\
\overrightarrow{\mid} \\
\vec{q}+\end{array}$ & 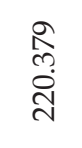 & 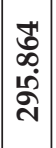 & $\begin{array}{l}\frac{D}{0} \\
\stackrel{\sim}{\sigma}\end{array}$ & $\begin{array}{l}\text { ন゙ } \\
\text { సે } \\
\text { }\end{array}$ & 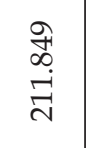 & 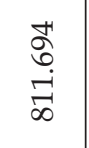 & 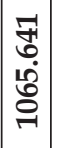 & & $\begin{array}{l}\text { ठे } \\
\text { c) }\end{array}$ & 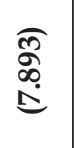 & 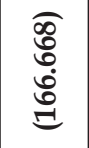 & 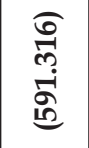 & 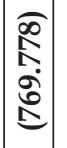 \\
\hline 芯 & $\mid \begin{array}{l}\hat{\alpha} \\
\text { Ln } \\
\text { Ln }\end{array}$ & 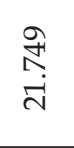 & 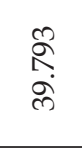 & $\begin{array}{l}\text { Dे } \\
\text { مై } \\
\text { ర్ర }\end{array}$ & 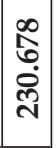 & مొ & 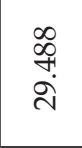 & 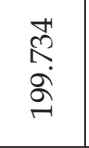 & 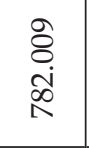 & 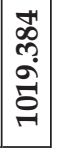 & & 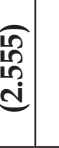 & 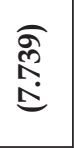 & 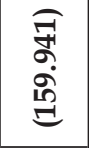 & 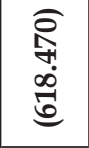 & 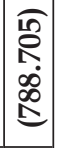 \\
\hline 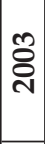 & $\begin{array}{l}\infty \\
\stackrel{\infty}{\sim} \\
\end{array}$ & $\begin{array}{l}\text { ने } \\
\text { ఫे } \\
\stackrel{6}{0}\end{array}$ & 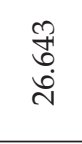 & 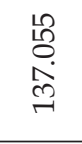 & 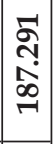 & 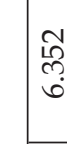 & $\begin{array}{l}\text { مิ } \\
\text { ลे }\end{array}$ & 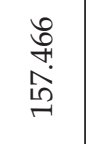 & 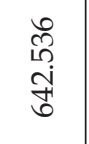 & 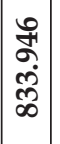 & & $\vec{\infty}$ & $\begin{array}{l}\text { त } \\
\stackrel{\infty}{-} \\
\stackrel{-}{\Xi} \\
=\end{array}$ & 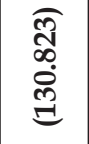 & 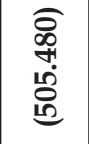 & 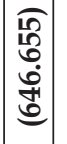 \\
\hline 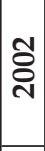 & 章 & 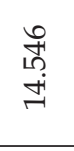 & $\begin{array}{l}\frac{2}{\alpha} \\
\stackrel{\lambda}{\lambda}\end{array}$ & $\begin{array}{l}\text { d } \\
\stackrel{+}{+} \\
\exists\end{array}$ & 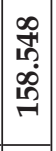 & ठํ. & 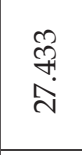 & $\begin{array}{l}\stackrel{8}{9} \\
\stackrel{0}{0} \\
\stackrel{0}{n}\end{array}$ & 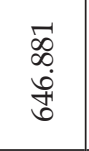 & \begin{tabular}{|c|c}
$\hat{R}$ \\
$\infty$ \\
$\infty$ \\
$\infty$ \\
\end{tabular} & & $\underset{F}{F}$ & $\begin{array}{l}\mathbb{E} \\
\infty \\
\stackrel{\infty}{+} \\
\stackrel{d}{d}\end{array}$ & 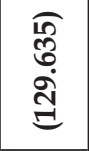 & 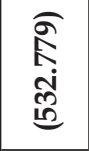 & 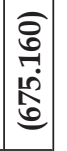 \\
\hline ర్స్రి & 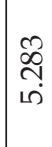 & 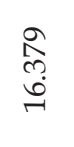 & $\begin{array}{l}\vec{\nabla} \\
\text { ลे }\end{array}$ & 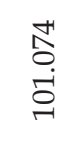 & $\mid$\begin{tabular}{c}
$\infty$ \\
\multirow{Z}{*}{} \\
in \\
\end{tabular} & $\begin{array}{l}\stackrel{N}{N} \\
\hat{0}\end{array}$ & $\begin{array}{l}\text { ఫे } \\
\text { ले } \\
\text { ते }\end{array}$ & 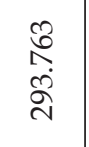 & \begin{tabular}{l} 
వి \\
\multirow{2}{*}{} \\
$\stackrel{0}{0}$
\end{tabular} & $\left|\begin{array}{c}0 \\
0 \\
0 \\
\infty \\
\sigma \\
\sigma\end{array}\right|$ & & 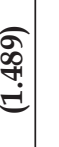 & $\begin{array}{l}\hat{\sigma} \\
\text { g. } \\
\stackrel{\Xi}{E}\end{array}$ & $\begin{array}{l}\text { त्र } \\
\text { ơ } \\
\text { ț. } \\
\text { d. }\end{array}$ & 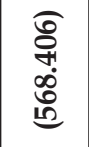 & 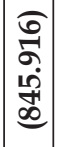 \\
\hline ఫ্ণী & సิ & 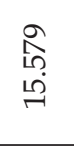 & $\begin{array}{l}\text { ஜ } \\
\text { \& }\end{array}$ & 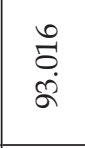 & 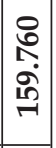 & 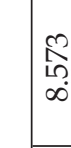 & 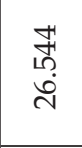 & $\begin{array}{l}\infty \\
\sigma \\
\vec{\sigma} \\
\vec{\nabla}\end{array}$ & $\begin{array}{l}\hat{0} \\
\stackrel{5}{0} \\
\text { ఫु }\end{array}$ & 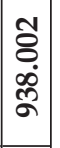 & & 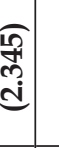 & 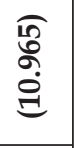 & 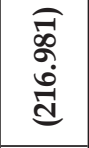 & 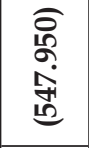 & 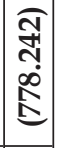 \\
\hline 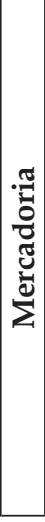 & 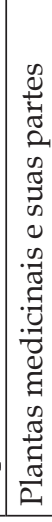 & 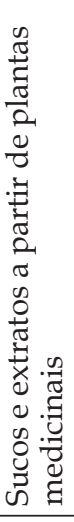 & 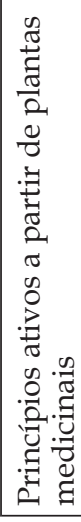 & 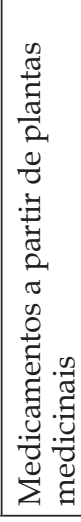 & $\mid \begin{array}{l}\vec{\pi} \\
0 \\
\hat{H}\end{array}$ & 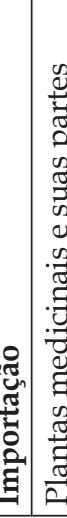 & 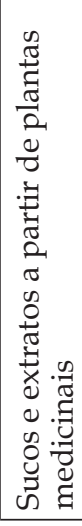 & 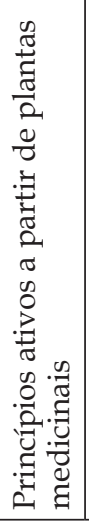 & 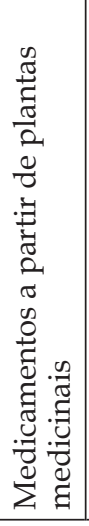 & $\mid \begin{array}{c}\pi \\
\stackrel{\pi}{0} \\
6\end{array}$ & 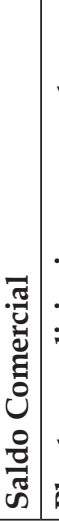 & 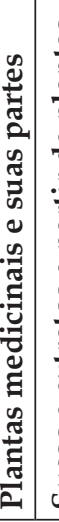 & 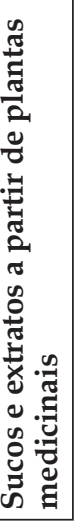 & 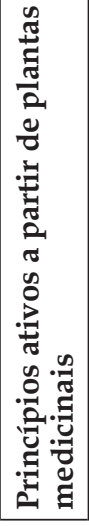 & 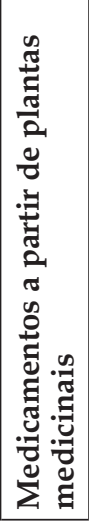 & 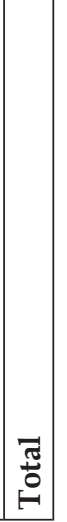 \\
\hline
\end{tabular}


Considerando, especificamente, o segmento das "plantas medicinais in natura", verificou-se que, entre 2000/2011, as exportações cresceram $88,0 \%$, enquanto as importações cresceram $137,7 \%$. O saldo da balança comercial saiu de um déficit de U\$2,3 milhões dólares para U\$ 8,7 milhões de dólares, ou seja, obteve um acréscimo de $325,8 \%$ no déficit do período abordado (Gráfico 1). Já no segmento dos "sucos e extratos a partir de plantas medicinais" verificou-se que, entre 2000/2011, as exportações decresceram $(95,2 \%)$, enquanto as importações decresceram $(6,9 \%)$. O saldo da balança comercial saiu de um déficit de U\$ $(11,0)$ milhões de dólares para (U\$ 24,0) milhões de dólares, ou seja, obteve um acréscimo de $118,6 \%$ no período abordado (Gráfico 2).

Considerando o segmento dos "princípios ativos a partir de plantas medicinas", verificou-se que, entre 2000/2011, as exportações cresceram $65,5 \%$, enquanto as importações decresceram $(37,3 \%)$. O saldo da balança comercial saiu de um déficit de $\mathrm{U} \$(217,0)$ milhões de dólares para U\$ $(89,8)$ milhões de dólares, ou seja, obteve um decréscimo de $(58,6 \%)$ no déficit do período abordado (Gráfico 3).

Já no segmento dos "medicamentos e fármacos a partir de plantas medicinais", verificou-se que, entre 2000/2011, as exportações cresceram $409,4 \%$, enquanto as importações cresceram $213,9 \%$. O saldo da balança comercial saiu de um déficit de U\$ $(547,9)$ milhões de dólares para U\$ $(1,7)$ bilhões de dólares, ou seja, obteve um acréscimo de $213,9 \%$ no déficit do período abordado (Gráfico 4). Nestes segmentos em particular, verificam-se dois processos simultâneos: 1) Um início do processo de substituição de importações dos princípios ativos a partir de plantas medicinais; 2 ) Um relativo fortalecimento nas exportações brasileiras de medicamentos a partir de plantas medicinais, o que demonstra uma relativa ampliação da competitividade brasileira no setor. Porém isso não retira a condição do Brasil de ser um grande importador líquido também nesse segmento da cadeia produtiva. Isto mantém a mesma tendência apontada no trabalho de Rodrigues e Nogueira (2008).

Gráfico 1 - Evolução do comércio exterior - plantas medicinais "In Natura" e suas partes (valores em mil US\$ FOB)

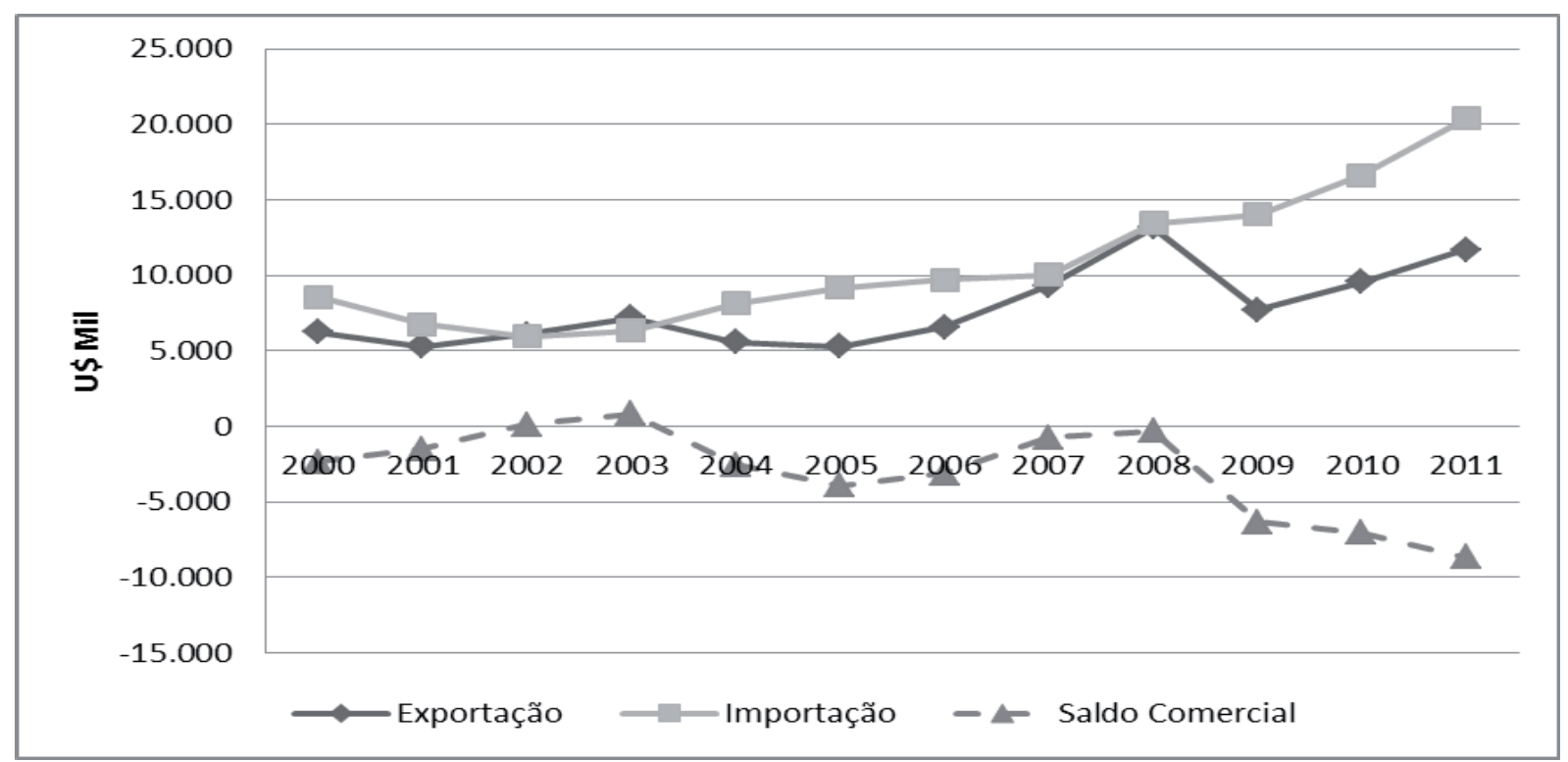

Fonte: Ministério de Desenvolvimento, Indústria e Comércio (MDIC) - Aliceweb. Dados trabalhados pelo autor 
Gráfico 2 - Evolução do comércio exterior - sucos e extratos a partir de plantas medicinais (valores em mil US\$ FOB)

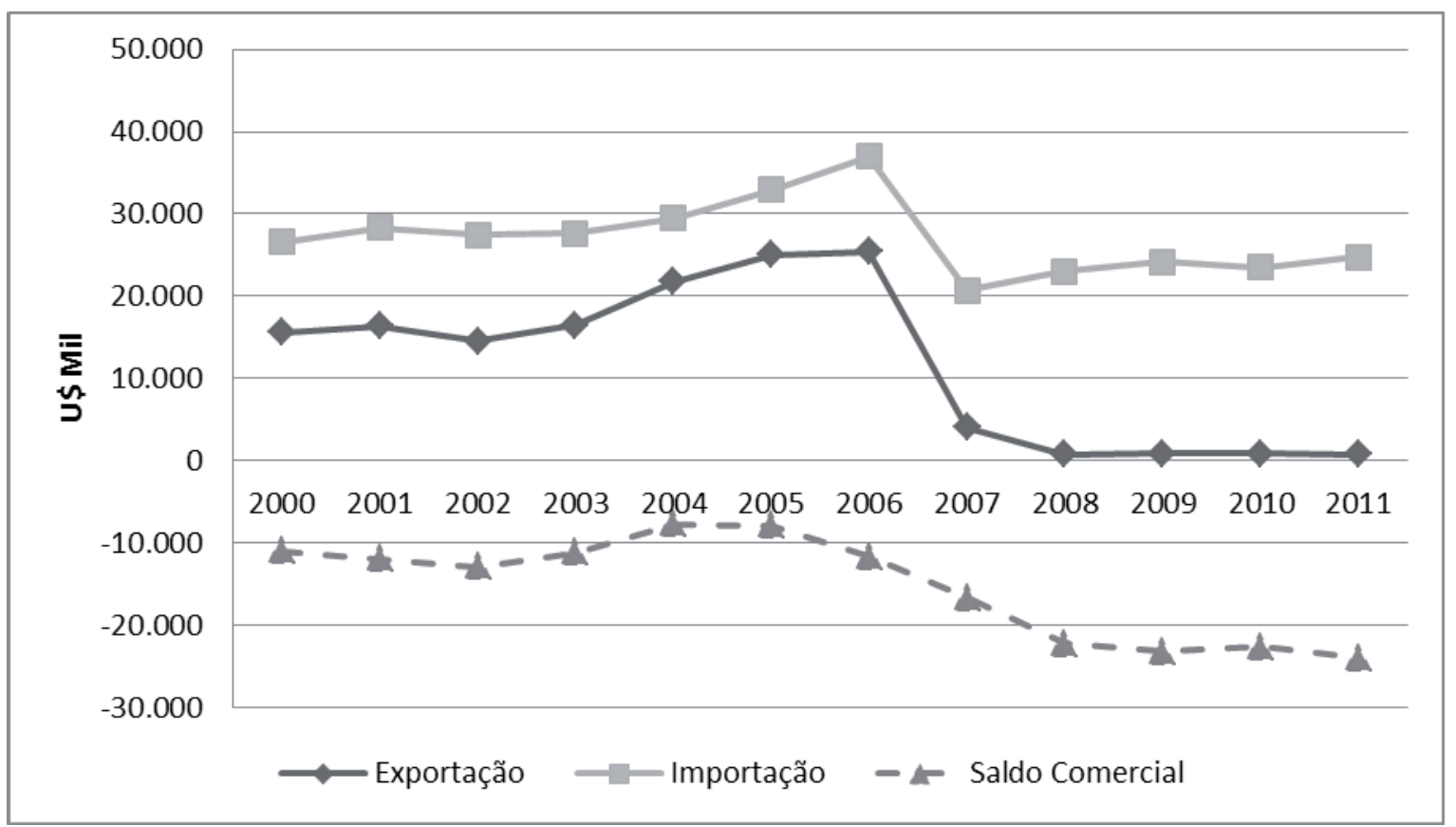

Fonte: Ministério de Desenvolvimento, Indústria e Comércio (MDIC, 2011) - Aliceweb. Dados trabalhados pelos autores.

Gráfico 3 - Evolução do comércio exterior - princípios ativos a partir de plantas medicinais (valores em mil US\$ FOB)

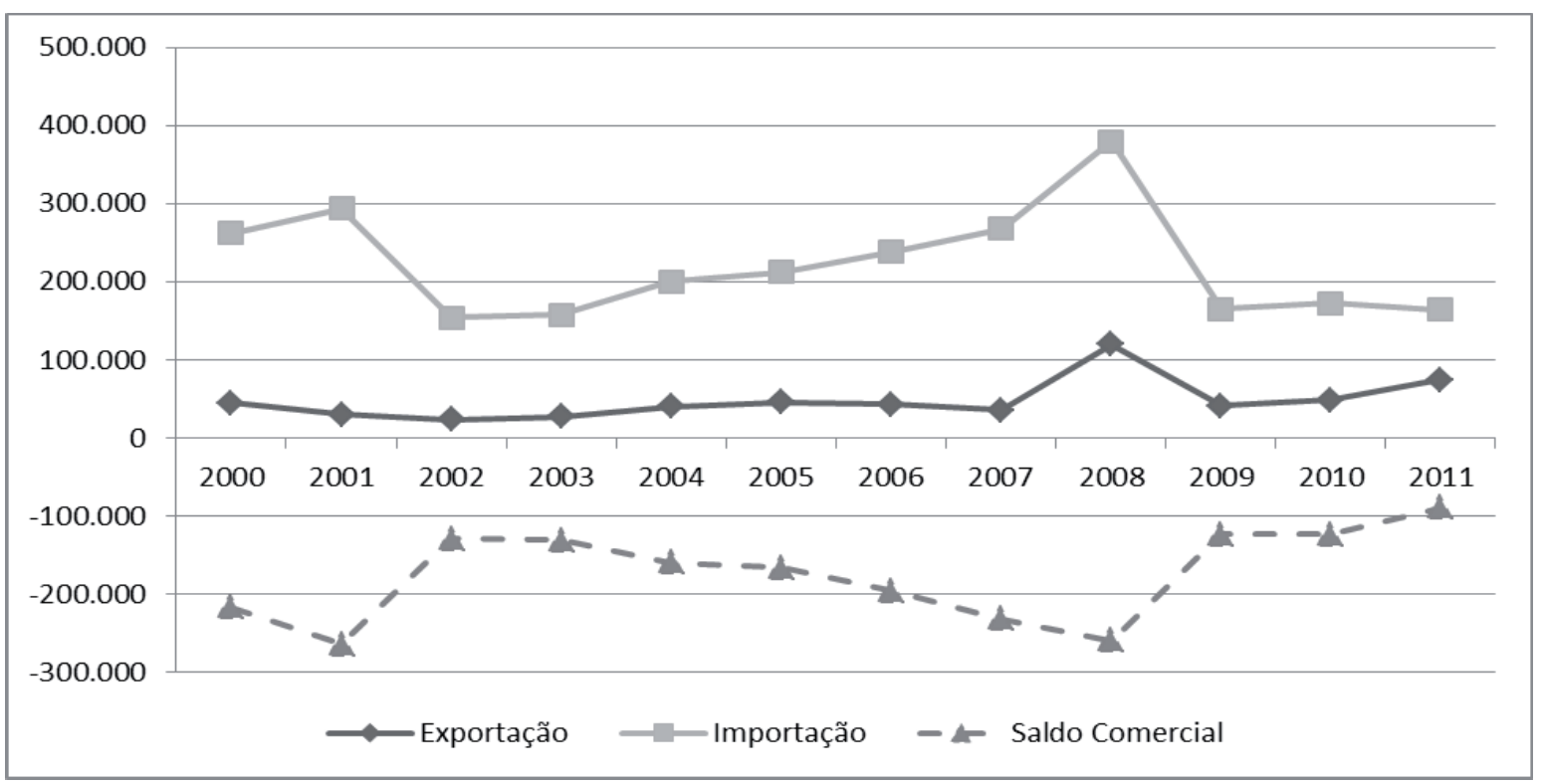

Fonte: Ministério de Desenvolvimento, Indústria e Comércio (MDIC, 2011) - Aliceweb . Dados trabalhados pelos autores. 
Gráfico 4 - Evolução do comércio exterior - medicamentos e fármacos a partir de plantas medicinais (valores em mil US\$ FOB)

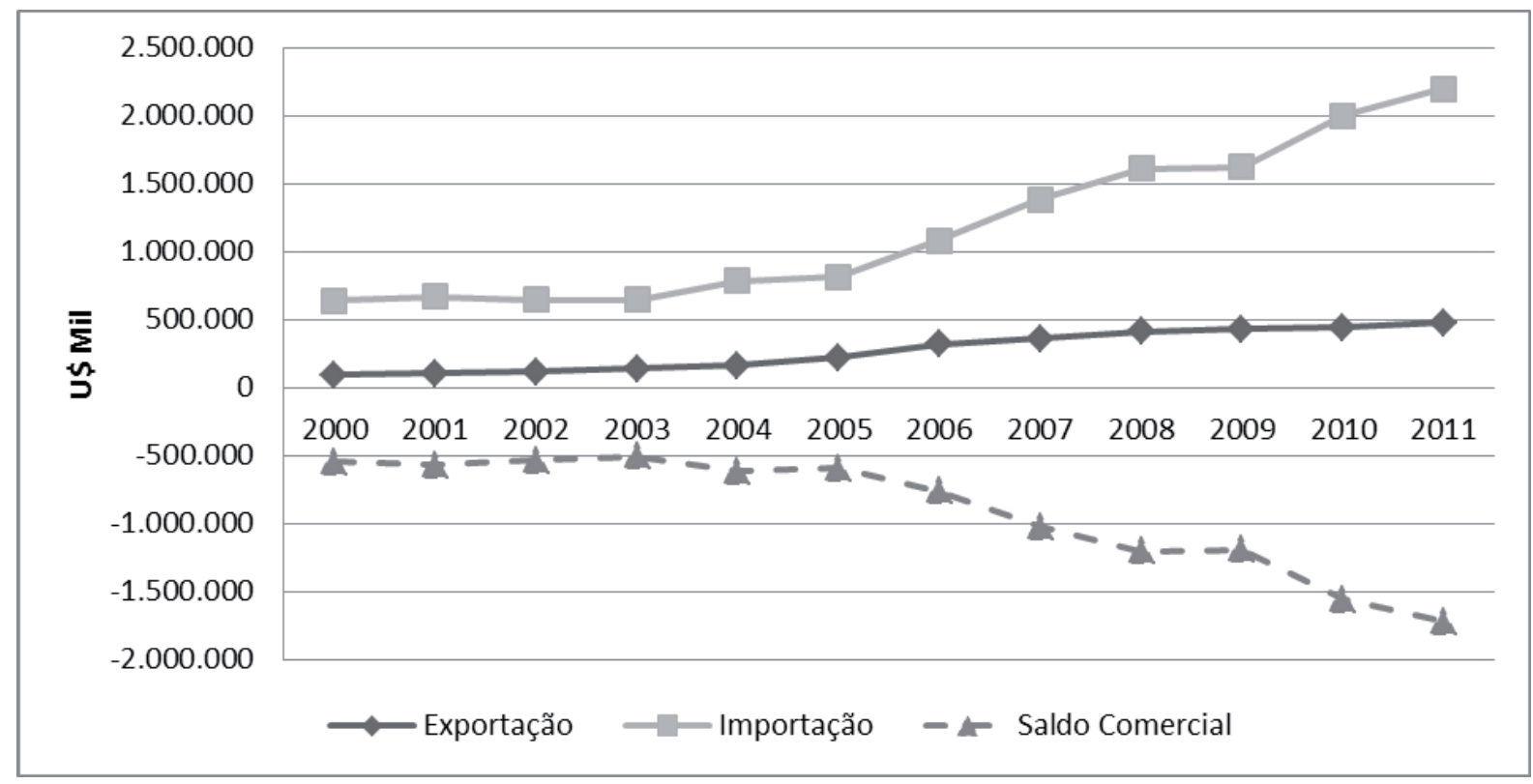

Fonte: Ministério de Desenvolvimento, Indústria e Comércio (MDIC, 2011) - Aliceweb. Dados trabalhados pelos autores.

\section{CONCLUSÃO}

O Brasil é um país com baixo nível de competitividade revelada na cadeia produtiva de plantas medicinais. É um tradicional importador líquido em todos os segmentos da cadeia produtiva. Rodrigues e Nogueira (2008) apontaram que, entre 1996-2006, o déficit comercial teve um acréscimo de 55,2\%. Já no período abordado aqui, 2000-2011, o mesmo déficit comercial ampliou 136,7\%, chegando a $\mathrm{R} \$ 1,8$ bilhões em 2011. Isto demonstra que o Brasil não conseguiu ainda alcançar um papel de protagonismo na competição internacional do setor, mesmo sendo um dos países com maior riqueza em biodiversidade do planeta.

A partir do ano de 2006, começaram a ocorrer grandes mudanças no marco regulatório e ambiente institucional relacionado ao de plantas medicinais e à fabricação de produtos nacionais e medicamentos fitoterápicos com a aprovação da Política Nacional de Práticas Integrativas e Complementares (PNPIC) no Sistema Único de Saúde (SUS) e a Política Nacional de Plantas Medicinais e Fitoterápicos (PNPMF), as quais fomentam pesquisas sobre plantas medicinais e desenvolvimento de fitoterápicos de qualidade, priorizando a proteção da biodiversidade.
Porém o grande salto no ambiente institucional foi dado em 2014, com a criação da categoria de "Produtos Tradicionais Fitoterápicos" (RDC 26/2014 - ANVISA). Esses produtos não necessitarão passar por testes pré-clínicos e clínicos, e serão autorizados por meio da demonstração do uso seguro no ser humano por um período longo, determinado pela Agência como de 30 anos, mediante a literatura científica referenciada.

Com isto ficará muito mais simples e bem menos onerosa a obtenção de registros para a fabricação de produtos tradicionais fitoterápicos, o que possibilitará um ambiente para o surgimento de novas oportunidades para as empresas. Antes da RDC 26/2014, somente era possível entrar de forma legal no setor, com um investimento mínimo aproximado de R $\$ 7$ milhões, agora será possível fabricar produtos tradicionais fitoterápicos, com investimentos abaixo de $\mathrm{R} \$ 1$ milhão de reais, isto obviamente dependendo da dimensão da planta produtiva, sem contar, as possibilidades que surgirão para a formação de cooperativas de produção nas comunidades tradicionais que detêm o saber popular das plantas medicinais.

Assim, espera-se um grande estímulo o setor com a criação dos produtos tradicionais 
fitoterápicos. Porém os desafios mais complexos no isolamento de princípios ativos para o fortalecimento da indústria nacional de medicamentos fitoterápicos ainda permanecerão. Todavia, com esta janela de oportunidade, o Brasil poderá avançar, e muito, no uso de sua biodiversidade com a geração de produtos de alto valor agregado. Sem dúvida, um grande avanço para nossa economia da biodiversidade, que, para ser mais bem aproveitada, depende do conjunto de outras políticas, mas grandes passos já foram dados.

Para pesquisas futuras, sugere-se acompanhar os efeitos da criação dos "Produtos Tradicionais Fitoterápicos", implantados pela RDC 26/2014, sobre a evolução do setor no país, especificando o tamanho das novas plantas que surgirão, natureza do capital (nacional ou estrangeiro) e forma de sociedade (anônima, limitada ou cooperativa). Também e desejável acompanhar como as comunidades tradicionais irão se inserir nessa nova janela de oportunidade para o melhor uso econômico da biodiversidade brasileira.

\section{REFERÊNCIAS}

ALVES, N. D. da Costa et al. Avaliação da adequação técnica de indústrias de medicamentos fitoterápicos e oficinais do estado do Rio de Janeiro. Ciênc. Saúde Coletiva, Rio de Janeiro, v. 13, supl., abr. 2008.

ASSOCIAÇÃO BRASILEIRA DAS EMPRESAS DO SETOR FITOTERÁPICO, SUPLEMENTO ALIMENTAR E DE PROMOÇÃO DA SAÚDE - ABIFISA. Informações sobre os fitoterápicos brasileiros, 2007. Disponível em: <www.abfisa.org.br>. Acesso em: 15 dez. 2015.

BRAGA, S. O uso sustentável da biodiversidade amazônica. In: VELLOSO, J. P. R.; ALBUQUERQUE, R. C. (Org.). Amazônia vazio de soluções? - desenvolvimento moderno baseado na biodiversidade. Rio de Janeiro: José Olympio, 2002.
BRASIL. Ministério do Desenvolvimento, Indústria e Comércio Exterior. Sistema Aliceweb: informações sobre o comércio exterior brasileiro. Brasília, 2007. Disponível em: <www.desenvolvimento.gov.br>. Acesso em: 3 jan. 2016.

CARVALHO, A. C. B. et al. Regulation of herbal medicines in Brazil: advances and perspectives. Braz. J. Pharm. Sci., São Paulo, v. 47, n. 3, jul./set. 2011, p. 467-473, 2011.

CARVALHO, A. C. B.; BALBINO, E. E.; MACIEL, A.; PERFEITO, J. P. S. Situação do registro de medicamentos fitoterápicos no Brasil. Rev. Bras. Farmacogn., João Pessoa, v. 18, n. 2, p. 314-319, abr./jun. 2008a.

CARVALHO, A. C. B.; SANTOS, L. A.; SILVEIRA, D. La regulación de los medicamentos herbarios en Brasil. Boletín Latinoamericano y del Caribe de Plantas Medicinales y Aromáticas, Santiago, v. 8, n. 1, p. 7-11, 2008b.

FERREIRA, S. H. (Org.). Medicamentos a partir de plantas medicinais no Brasil. Rio de Janeiro: Academia Brasileira de Ciências, 1998.

GADELHA, C. A. G. Desenvolvimento, complexo industrial da saúde e política industrial. Revista de Saúde Pública, v. 40, n. especial, p. 11-23, 2006.

. O complexo industrial da saúde e a necessidade de um enfoque dinâmico na economia da saúde. Ciência Saúde Coletiva, v. 8, n. 2, p. 521-535, 2003.

LAZZARINI, S. G.; CHADDAD, F. R.; COOK, M. L. Integrating supply chain and network analyses: the study of netchains. Journal on Chain and Network Science, Wageningen, v. 1, n. 1, p. 7-22, 2001. Acesso em: 3 jan. 2016.

MINISTÉRIO DO DESENVOLVIMENTO, INDÚSTRIA E COMÉRCIO - MDIC. Sistema Aliceweb: informações sobre o comércio exterior brasileiro. Brasília: MDIC, 2011. Disponível em: <www.desenvolvimento.gov.br>. Acesso em: 5 jan. 2016.

NÚCLEO de Economia Industrial e da Tecnologia. Estudo de competitividade por cadeias integradas no Brasil: complexo da saúde. Campinas: UNICAMP, 2002.

RODRIGUES, W.; NOGUEIRA, J. M. Competitividade da cadeia produtiva de plantas medicinais no Brasil: uma perspectiva a partir do comércio exterior. Informe Gepec. Toledo: v. 12, n. 2, p. 91-105, jul./dez. 2008.

YUNES, R. A.; PEDROSA, R. C.; CECHINEL-FILHO, V. Fármacos e fitoterápicos: a necessidade do desenvolvimento da indústria de fitoterápicos e fitofármacos no Brasil. Quím. Nova, v. 24, n. 1, p. 147-152, 2001. 